\title{
Distributed Hydrological Modeling of a Monsoon Dominated River System in Central Vietnam
}

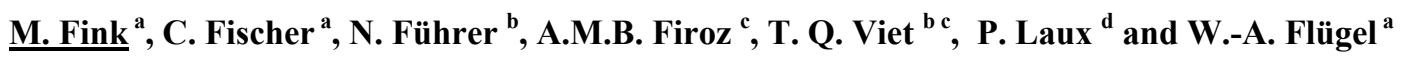 \\ ${ }^{a}$ Department of Geoinformatics, Modelling and Hydrology, Institute for Geography, Friedrich-Schiller \\ University Jena \\ Email: manfred.fink@uni-jena.de \\ ${ }^{b}$ Department of Environmental Engineering and Ecology, University of Bochum \\ ${ }^{c}$ Institute for Technology and Resources Management in the Tropics and Subtropics (ITT) \\ Cologne University of Applied Sciences \\ ${ }^{d}$ Department "Interaction Climate-Atmosphere", Research Group "Climate Change and Terrestrial \\ Hydrology", Karlsruhe Institute of Technology (KIT), Institute for Meteorology and Climate Research \\ Atmospheric Environmental Research (IMK-IFU)
}

\begin{abstract}
Vietnam is regarded as a country which is strongly impacted by climate change. Population and economic growth result in additional pressures on the ecosystems in the region. The water balance is stressed particularly by the construction and operation of hydropower dams, urbanization, and increasing demands for water by its industries and inhabitants. The Vu Gia-Thu Bon watershed catchment located in central Vietnam, impacted by a tropical monsoon climate and with an area of $12,000 \mathrm{~km}^{2}$. In order to assess the impacts of climate and land-use changes, the distributed hydrological model J2000 was used to simulate the water balance of this catchment. J2000 incorporates the various hydrological processes and is available through the JAMS (Jena Adaptable Modeling System) modeling framework developed at the University of Jena. Due to the lack of measurement data, parameter transfers were performed from one sub-catchment to the entire catchment area. The results and statistical objective functions indicate that the model and the parameter transfers are able to simulate adequately the hydrological system of the catchment. In the next step the distributed model results are used by hydro dynamic models (Mike 11 and Mike Flood) and Mike Basin, all developed and supported by the Danish Hydraulic Institute (DHI). Although Mike-11 and Mike Flood simulate flood and saltwater intrusion dynamics in the rivers, Mike Basin is used to estimate the effects of actual and proposed hydropower facilities and other hydrological infrastructure.

For projecting future climate-change, results of WRF (Weather Research and Forecasting) downscale simulation will be used. Also, various scenarios of land-use change will be used to project future development in the catchment area. The results of the J2000 simulation will provide national and local stakeholders with information for decision support in land-use and hydrological-management issues.
\end{abstract}

Keywords: Distributed hydrological modeling, model coupling, parameter transfer, central Vietnam 


\section{INTRODUCTION}

Central Vietnam is located in the region of the south East Asia monsoon. It is suspected to be a region that is strongly impacted by the global change. The pressure on the water resources is increasing due to population and economic growth in the region. Especially processing industry and tourism are expanding sectors in the region. A further modification of the water resources in this area is driven by the rapid development of hydropower. To estimate the impact of these changes and to give decision support to the national and regional stakeholders the German Federal Ministry of Education and Research funded project LUCCI (Land Use and Climate Change Interactions in central Vietnam) is established.

The most important problems related to hydrology in the area are flooding due to typhoon storm events in the wet season. In the dry season salt water intrusion in the estuaries is the important problem. The irrigated areas close to the sea are supplied by the water taken from these estuaries. In the case of salt water intrusion the pumping stations have to stop the operation and as a consequence a deficit of irrigation water seriously affects the agricultural production. Both problems are influenced by the hydrological infrastructure especially from the expanding hydropower. To represent the above mentioned aspects several models are utilized. For the flood dynamics in the flood plain the two dimensional hydrodynamic model Mike Flood (DHI, 2007) is used whereas the problem of salt water intrusion in estuaries of the rivers is estimated with the one dimensional hydrodynamic model Mike 11 (DHI, 2001). The impact of hydrological infrastructure like hydropower reservoirs will be assessed with Mike Basin (DHI, 2006). These models depend on runoff values either from measurements or from empirical rainfall runoff models, included in the Mike modeling suite. These simple models are not well suited to represent the impact of land use and climate change, because they are strongly relying on the measured input-output relationship, which is of course not available for the future developments. Therefore the distributed process based model JAMS/J2000 (Krause, 2001, 2002) is used to describe the impact of climate and land use change on the hydrology of the area. Since the processes in the model are described by parameters with physical meaning, changes could be described. The distributed output from the J2000 model is used to drive the Mike models. The paper focusses on the J2000 modeling.

\section{DESCRIPTION OF THE STUDY AREA}

The study area consists of the Vu Gia and Thu Bon (VGTB) river system catchment, located in the two provinces of Quang Nam and Da Nang. The size of the site is approx. $12000 \mathrm{~km}^{2}$ and it is located in central Vietnam (cf. Figure 1.).

Located in the south of the Thua Thien-Hue Province and in the east of Laos, the climate in the VGTB river basin shows the South Central Vietnamese climate. It features relatively warm winters, dry summers and a strong monsoon impacted rainy season with typhoons lasting from September to December (Souvignet et al. 2012). The precipitation varies between 2300 and $5600 \mathrm{~mm}$ per year. About $65-80 \%$ of this amount accounts for the wet season between September and December.

The study area consists of three different landscape types (altitude bands) which can be approximately defined in the following way:

- The Uplands are dominated by natural and production forests. Agriculture is dominated by shifting cultivation with about seven years of acacia trees (used for wood and pulp production) and about three years of crops like soybean, fruits or vegetables. On the few high plateaus irrigated rice is planted, also. The altitude for this landscape ranges approx. from $800 \mathrm{~m}$ to $2500 \mathrm{~m}$ a.s.1..

- In the Midlands the shifting cultivation is more frequent but some forests still exist. The importance of rubber plantations have increased during the last years. In the valleys irrigated paddy rice is the dominating crop. The Midlands are approximately located between $800 \mathrm{~m}$ and $200 \mathrm{~m}$ a.s.1..

- The Lowlands are dominated by the irrigated rice production. Occasionally other crops are cultivated especially in the higher elevated parts of the irrigation districts. The bigger settlements and infrastructure are also located in the lowlands. The river system in the lowlands exhibits many different rivers connected by natural and artificial cannels. Most of them are influenced by tidal dynamics. The lowlands starts at sea level and reach approx. $200 \mathrm{~m}$ a.s.1.. 


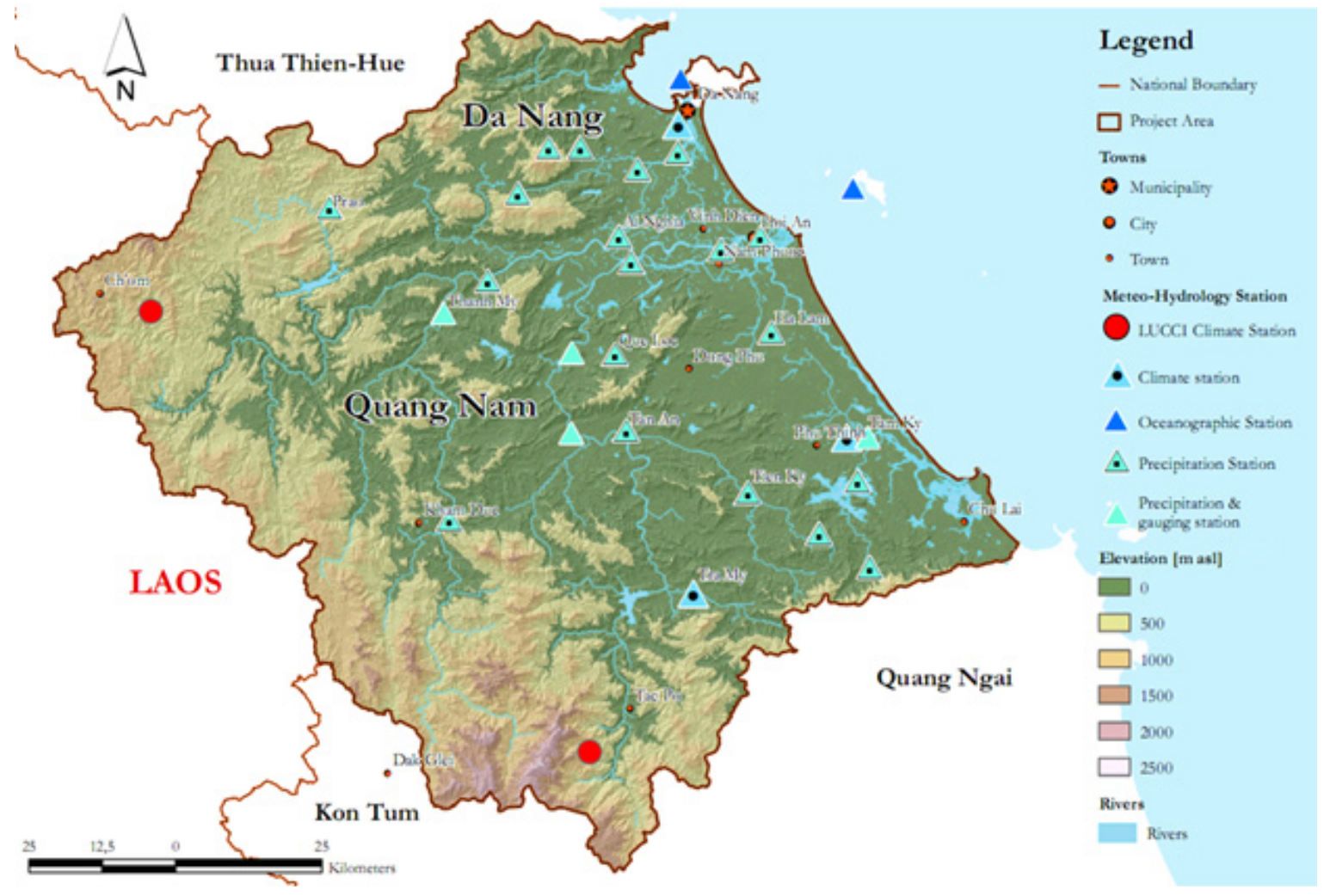

Figure 1. Study area: Provinces Quang Nam and Da Nang and the catchment of the river system Vu Gia and Thu Bon plus the hydro-meteorological measurement network.

\section{METHODS AND MATERIAL}

\subsection{Available Data and Data Preparation}

Within the catchment 21 precipitation stations and three climate stations with data from 1979 till 2010 are available. The climate stations are located in the lowlands and only a few precipitation stations are located at higher altitudes. For the LUCCI-Project we established two climate stations in the highlands to estimate the influence of the altitude on the climate elements (cf. Figure 1). This is an ongoing task because the gathered time series are still too short for analyses. For the study area's river system 10 gauging stations are available, but only two of them measure discharge values continuously. The other eight stations are located in the lowlands: as the rivers there are tidal influenced, they measure water level only. The time series data were checked for homogeneity and plausibility and converted into a format readable by J2000 (Krause, 2001, 2002).

For the description of soils, a map at the scale of 1:100,000 was available (National Institute of Agriculture Planning and Protection, 2005). In addition, 150 soil profile descriptions in the catchment were available to derive soil-model parameters for the various soil classes described in the map. The geology is also described by a map in a scale of 1:100,000 (Department of Geology and Minerals of Vietnam, Hanoi, 1997). For land use, a land-cover classification of Landsat images for the year 2010 was used. The digital elevation model (DEM) was derived from contour lines and points from a digital map (scale 1:50,000) using the topographyto- raster algorithm of ArcGIS. The resulted DEM had a resolution (cell size) of $25 \mathrm{~m}$.

The spatial representation of the model is utilizing the HRU (Hydrological Response Units) approach (Flügel et al, 1997). This approach is enhanced by individual polygons (c.f. Figure 2, detail window) with a multidimensional routing scheme (Pfennig et al, 2009). The HRUs are the result of overlay analyses of the DEM derivates, Topographical Wetness Index, Mass Balance Index and Annual Solar Radiation Index and the individual soil classes. The land use and geology maps were just used to assign the according properties to the resulting polygons by using a maximum membership function. This had two reasons: firstly land use classification is too fine grained and noisy for an overlay analysis. Their use would result in too many HRU polygons for the modeling. Secondly, the features geology is quite similar to the soil map, such that the 
variability is already represented in the soil map. The HRU delineation process resulted in 477888 HRUs and 24192 reach segments for the entire VGTB basin.

\subsection{Modeling System JAMS/J2000}

J2000 can be classified as a distributed, process-oriented hydrological model for hydrological simulations of meso-scale and macro-scale catchments. It is implemented in the Jena Adaptable Modeling System (JAMS) framework (Kralisch and Krause, 2006; Kralisch et al, 2007), which is a software framework for componentbased development and application of environmental models. The model describes the hydrological processes as encapsulated or independent process modules. These modules describe for example input data regionalization and correction, calculation of potential and actual evapotranspiration, canopy interception, soil moisture and groundwater processes.

\subsection{Modeling Strategy}

The main objective of the modeling exercise is to simulate the watershed dynamics of the study area, because this is as a necessary precondition for the simulation of floods and saltwater intrusion by the hydro dynamic river models. These models require distributed model output with a high resolution. To meet this requirement we used a high spatial resolution for the hydrological simulation. Unfortunately current limits of hard- and software did not allow too delineate the spatial representation of the catchment (HRUs) directly. Thus we split the catchment into different sub-catchments. Those sub-catchments were defined by different gauging stations and different river mouths to the sea. Each of the resulting sub-catchments was then modeled separately (cf. Figure 2).

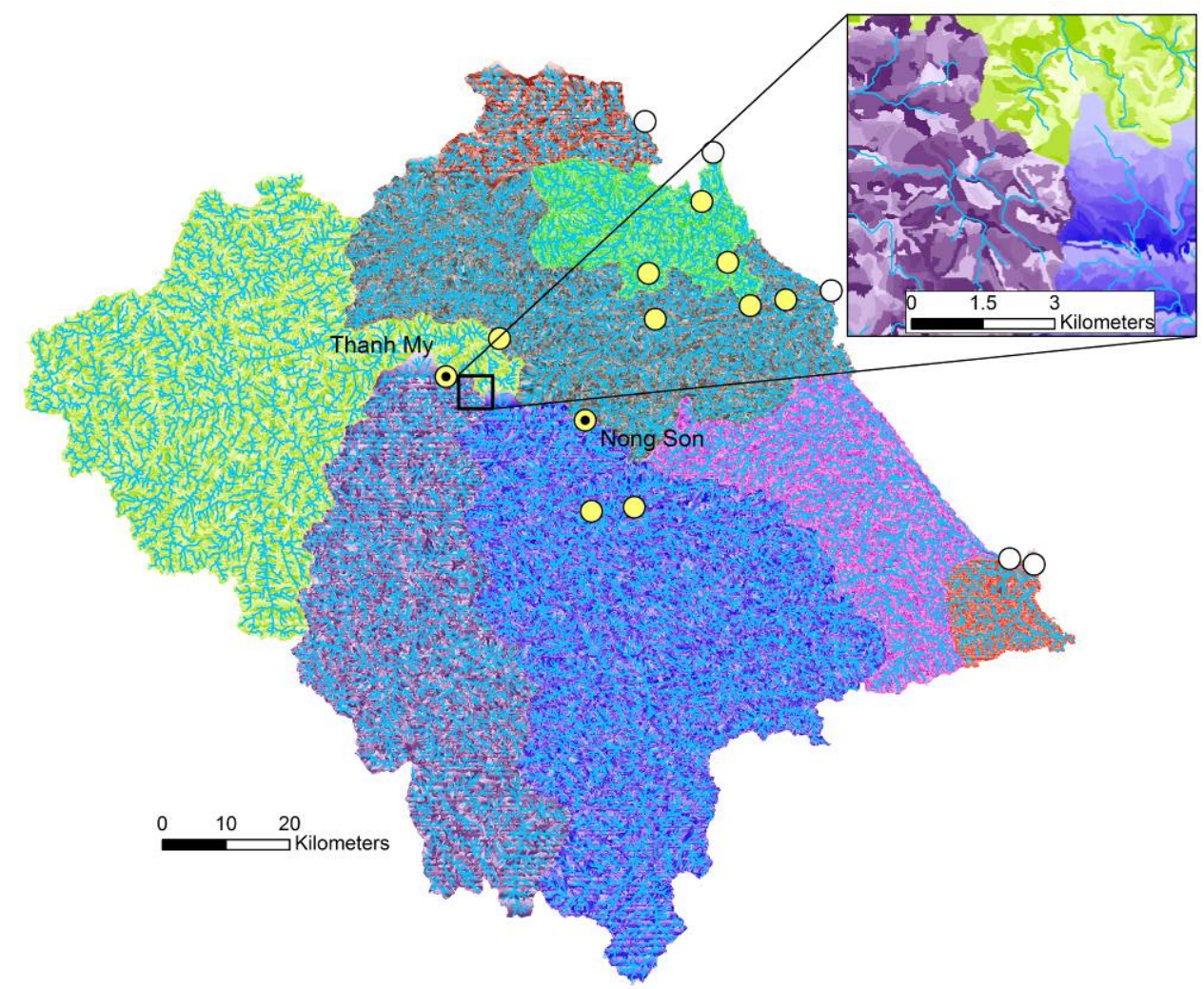

Figure 2. HRUs and reaches of the separately modeled sub catchments in the test site. Yellow dots indicate gauging stations with water level, with black dot representing additional runoff information. White dots indicate river mouths to the sea.

Another challenge was that the small number of discharge stations constrains the modeling strategy. Therefore we decided to calibrate the model parameters at only one discharge station. The data from the second station was used to validate parameter transfer to the entire test site. 


\section{RESULTS}

\subsection{Modeling results}

The simulated and measured runoff values for the validation period (from $1^{\text {st }}$ November 2000 to 31 th October 2005) are shown in Figure 3. The left diagram displays the hydrographs for the $3208 \mathrm{~km}^{2}$ large sub catchment
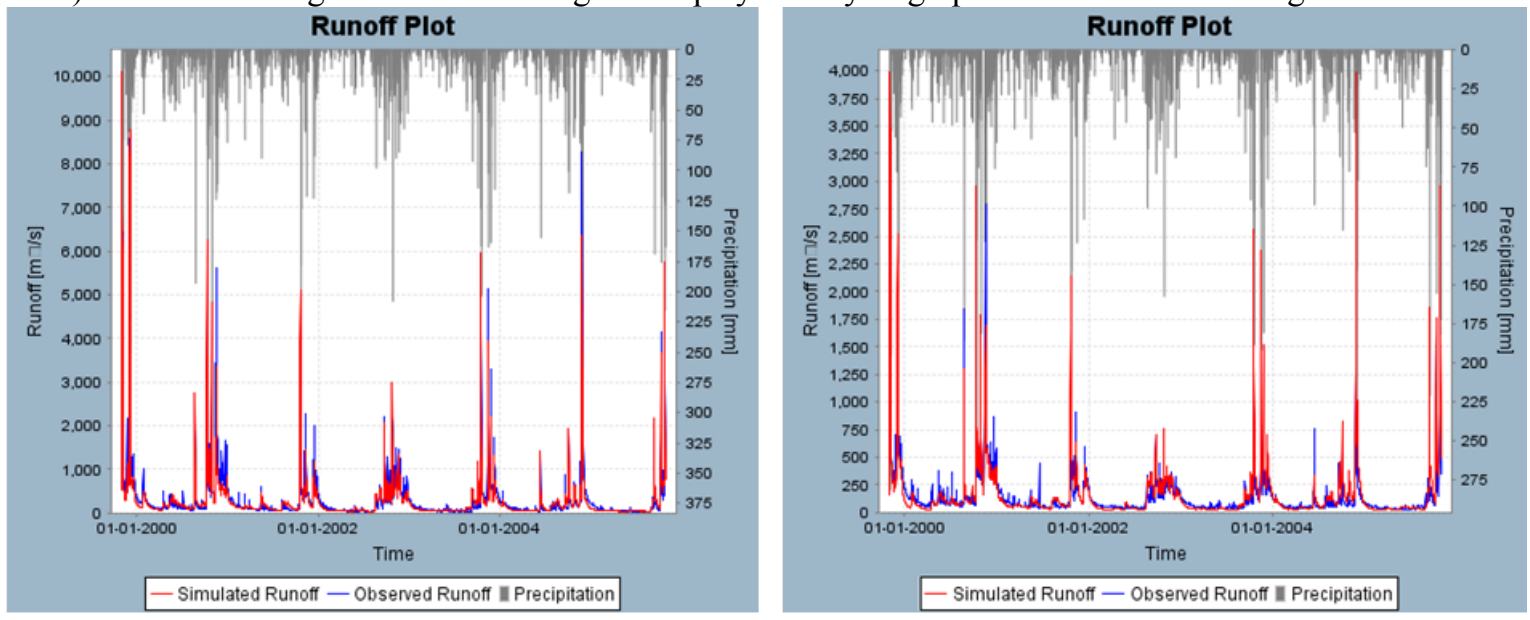

Figure 3: Modeled and measured discharge and precicitation from the two catchments of the Thu Bon River (Gauge Nong Son) and from the Vu Gia River (Gauge Thanh My) for the validation period (1st November 2000 - 31th October 2005).

of the Thu Bon River at Gauge Nong Son, whereas the right diagram shows the hydrographs for the other sub catchment (size $2047 \mathrm{~km}^{2}$ ) where runoff is continuously measured of the Vu Gia River at Thanh My (cf. Figure 2). In both diagrams a good agreement of measured and simulated hydrographs is shown. During the manual calibration we focused on the low flow periods. Table 1 shows the values of the efficiency functions. High values of the logarithmic Nash-Sutcliffe efficiency (logE2) reflect the good agreement of the low flow periods. High values of the standard NashSutcliffe efficiency (E2) confirm a good agreement for the medium and high flows (Krause et al 2005).

Table 1. Efficiency functions for the models in VGTB; E2, Nash-Sutcliffe efficiency, logE2 Nash-Sutcliffe efficiency with logarithmic values, $\mathrm{R}^{2}$, coefficient of determination and Pbias, relative volume error in percent.

\begin{tabular}{|c|c|c|c|c|}
\hline $\begin{array}{c}\text { River } \\
\text { (Gauging station) }\end{array}$ & \multicolumn{2}{|c|}{$\begin{array}{c}\text { Thu Bon } \\
\text { (Nong Son) }\end{array}$} & \multicolumn{2}{c|}{$\begin{array}{c}\text { Vu Gia } \\
\text { (Thanh My) }\end{array}$} \\
\hline Period & Calibration & Validation & "Calibration" & Validation \\
& $01.11 .1996-$ & $01.11 .2000-$ & $01.11 .1996-$ & $01.11 .2000-$ \\
& 31.10 .2000 & 31.10 .2005 & 31.10 .2000 & 31.10 .2005 \\
\hline E2 & 0.8647 & 0.8696 & 0.7696 & 0.6647 \\
\hline $\operatorname{logE2}$ & 0.8501 & 0.8450 & 0.7619 & 0.6956 \\
\hline $\mathrm{R}^{2}$ & 0.8683 & 0.8755 & 0.8364 & 0.8021 \\
\hline Pbias & -12.83 & -10.37 & 0.81 & 11.54 \\
\hline
\end{tabular}

The high values of the

coefficient of determination $\mathrm{R}^{2}$ show that the overall runoff dynamics are represented well $\left(\mathrm{R}^{2}>0.8\right.$ for all periods). Furthermore the total water balance represented by the relative volume error in percent (pbias) shows an under estimation of discharge for the Thu Bon River for both the validation and calibration period. The Thu Bon sub catchment contains most of the high elevated areas in the total catchment. Normally an increase of precipitation is observed at higher altitudes which are not represented by the existing precipitation measurement network as mentioned in section 3.1.Therefore it is likely that the systematic under prediction of the water balance is related to the lack of high elevated climate stations. In summary, the values for the objective functions indicate worse, but still satisfying results for the $\mathrm{Vu}$ Gia sub catchment so that the parameter transfer from the Nong Son sub-catchment to Thanh My sub-catchment was successfully applied.

\subsection{Model linkage}

The purpose of the simulation with $\mathrm{J} 2000$ was to represent the hydrological process dynamics of the catchment area, because this is the precondition to quantify the impact of land use and climate change on flood generation and salt water intrusion. 
Due to the distributed characteristic of the J2000-model and the capabilities of the JAMS modelling framework it is possible to output hydrological state variables for each point in time and space. This feature enables to transfer daily runoff time series at well suited points along the river segments to the models mentioned in section 1. In Figure 4 the transfer points for the different models are displayed. In the case of the salt water intrusion model (Mike 11) the main inlets to the estuaries are chosen (blue dots in the north eastern part) as main input of the system. Additionally the segments (blue bold lines) of the main stem of the rivers have been used to represent the water fluxes from the local catchments in the lowlands. Therefore the net flux for the reach segments was calculated by:

$\mathrm{Q}_{\text {net }}=\mathrm{Q}_{\text {seg }}-\mathrm{Q}_{\text {seg-1 }}$

Where Qnet represents the net flux, Qseg represents the runoff of the reach segment, and Qseg-1 equals the runoff of the associated reach segment located just upstream. The blue dot in the more southern part of the study area was selected to estimate the influence of a new constructed reservoir. For the Mike Flood model, the mainstream headwaters of the rivers have been chosen for the first realization of the model (red dots). Most of the transfer points are used by the Mike Basin Model (green dots). A subset of these points represents the major sub-catchments of the study area. The other part represents important components of the hydraulic infrastructure facilities, such as hydropower dams, irrigation reservoirs, pumping stations, and weirs.

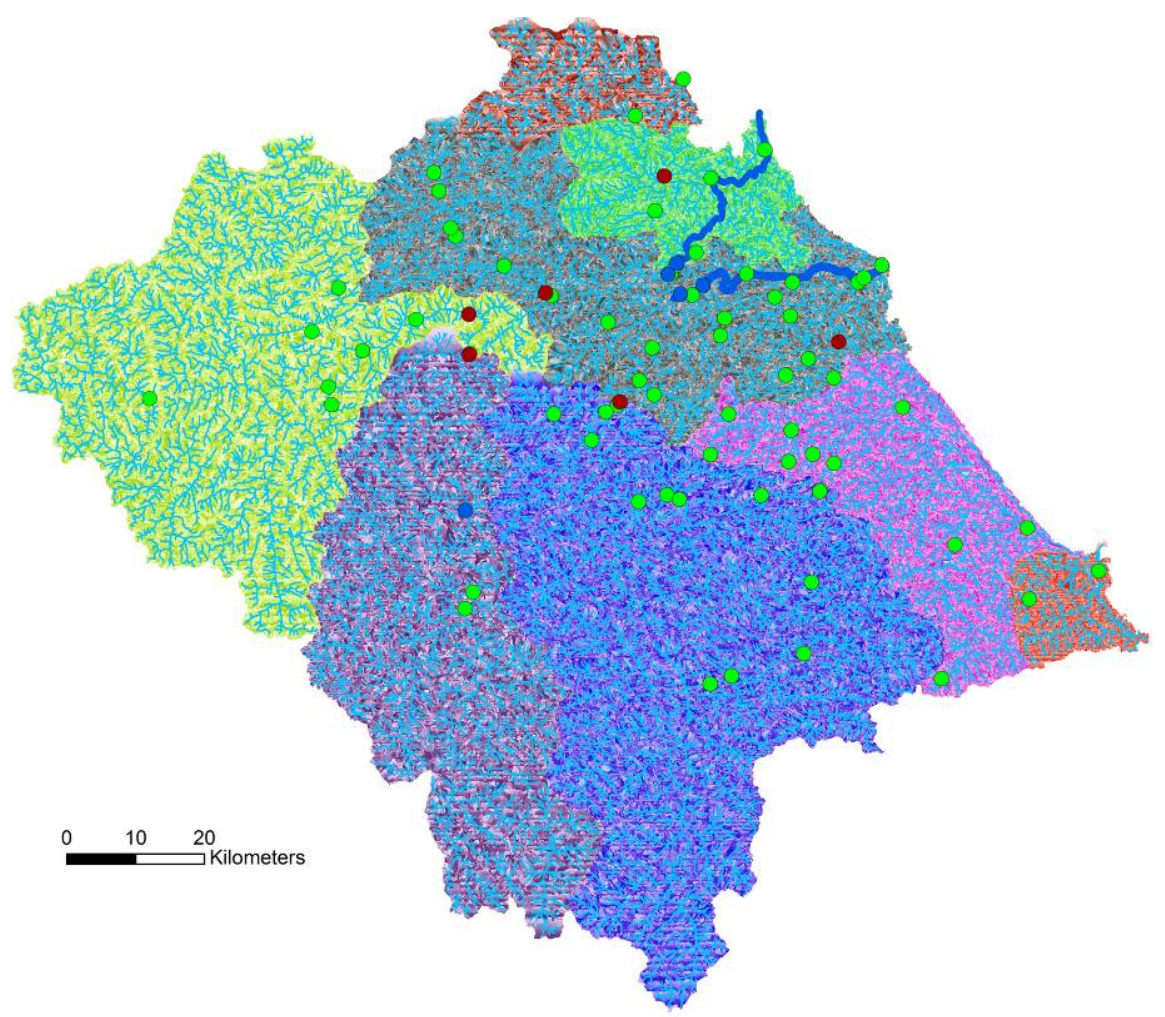

Figure 4: Locations for the transfer of J2000 result data to the hydrodynamic models Mike11 (blue dots and blue bold lines) and Mike flood (red dots) and the hydrological infrastructure model Mike Basin (green dots)

\section{FUTURE STEPS AND CONCLUSION}

We established a distributed process based hydrological model of the Vu Gia Thu Bon river system in central Vietnam. It is the first time that a model of this kind was used in this region. The results show that the model works quite well, so that the results can be used to drive other models to answer the questions about floods, saltwater intrusion and the influence of hydrological infrastructure.

The next step in modeling will include additional validation at some of the gauging stations in the lowlands. Therefore the measured water level will be used to compare the dynamics with the simulated runoff in the 
lowlands. Furthermore for some of the gauging stations in the lowland some discharge time series exist for the wet season which will be also compared with the modeled results.

The effect of land use change will be simulated by changing the land use type of the HRUs according to some land use scenarios. The land use scenario will be combined with climate change scenarios. These are provided by WRF (Weather Research and Forecasting) (Skamarock and Klemp, 2008) downscaling models in spatial resolution of approx. $5 \mathrm{~km}$ by $5 \mathrm{~km}$ based on ECHAM5 (European Centre for medium-range weather forecasts and HAMburg) (Roeckner et al, 2003) A1B and B1 scenarios (Laux et al. 2012).

\section{ACKNOWLEDGMENTS}

This research is funded the German Federal Ministry of Education and Research funds within the research project LUCCI (Land use and climate change interactions in central Vietnam). We also thank our Vietnamese partners especially from CTIC and IMHEN for the fruitful cooperation and the 3rd party independent reviewer as well as paper reviewer.

\section{REFERENCES}

DHI (2001), MIKE 11 Reference manual, Appendix A. Scientific background, Danish Hydraulic Institute.

DHI (2006), MIKE BASIN User's Manual. Copenhagen, Denmark, DHI Water and Environment.

DHI (2007). MIKE FLOOD - combined 1D and 2D hydrodynamic modelling (based on MIKE 11 and MIKE 21) for detailed inland flooding and storm surge studies. 2007 Release by DHI Water and Environment Agern Alle 5, DK-2970 Horsolm.

Kralisch, S. and Krause, P. (2006). JAMS - A Framework for Natural Resource Model Development and Application. Proceedings of the iEMSs Third Biannual Meeting (A. Voinov, A. Jakeman \& A. E. Rizzoli, eds.). Burlington, USA.

Kralisch, S., Krause, P., Fink, M., Fischer, C. and Flügel, W.-A. (2007). Component based environmental modelling using the JAMS framework. Proceedings of the MODSIM 2007 International Congress on Modelling and Simulation (D. Kulasiri \& L. Oxley, eds.). Christchurch, New Zealand.

Krause, P. (2001). Das hydrologische Modellsystem J2000 Beschreibung und Anwendung in großen Flugebieten, Schriften des Forschungszentrums Jülich, Reihe Umwelt/Environment, 29.

Krause, P. (2002). Quantifying the impact of land use changes on the water balance of large catchments using the J2000 model, Physics and Chemistry of the Earth, 27, 663-673.

Krause, P., Boyle, D. P. and Bäse F. (2005), Comparison of different efficiency criteria for hydrological model assessment. Advances in Geosciences, 5, 89-97.

Laux, P., Phan, V.T., Lorenz, Ch., Thuc, T., Ribbe, L., Kunstmann, H. (2012), Setting up Regional Climate Simulations for Southeast Asia. High Performance Computing in Science and Engineering' 12, Conference Proceedings, Wolfgang E. Nagel, Dietmar B. Kröner, Michael M. Resch (Eds.), Springer, pp 391-406.

Pfennig, B., Kipka, H., Wolf, M., Fink, M., Krause, P. and Flügel, W. A. (2009): Development of an extended spatially distributed routing scheme and its impact on process oriented hydrological modelling results. Joint IAHS \& IAH International Convention, Hyderabad Vol. 333, 37-43.

Roeckner, E., Bäuml, G., Bonaventura, L., Brokopf, R., Esch, M., Giorgetta, M., Hagemann, S., Kirchner, I., Kornblueh, L., Manzini, E., Rhodin, A., Schlese, U., Schulzweida, U., and Tompkins, A., (2003), The atmospheric general circulation model ECHAM5, Part I: Model description, MPI Report, 349.

Skamarock, W. C. and Klemp, J. B. (2008), A time-split nonhydrostatic atmospheric model for weather research and forecasting applications, Journal of Computational Physics, 227, 3465-3485.

Souvignet, M., Laux, P., Freer, J., Cloke, H., Thinh, D. Q., Thuc, T., Cullmann, J., Nauditt, A., Flügel, W.A., Kunstmann, H. and Ribbe, L. (2013), Recent climatic trends and linkages to river discharge in Central Vietnam. Hydrological Processes. doi: 10.1002/hyp.9693. 